\title{
O Potencial de Coalbed Methane (CBM) na jazida da Santa Terezinha - modelagem 3D e avaliação do poço de exploração CBM001-ST-RS
}

\author{
Wolfgang Kalkreuth ${ }^{1}$, Michael Holz, Junia Casagrande ${ }^{1}$, Rodrigo Cruz ${ }^{1}$, Tiago Oliveira ${ }^{1}$, \\ Marcio Kern ${ }^{1}$, Janaina Levandowski ${ }^{1}$ \& Silvia Rolim ${ }^{1}$
}

\begin{abstract}
Resumo O objetivo do estudo é avaliar o potencial de gás metano das camadas de carvão (CBM) na jazida de Santa Terezinha da Bacia do Paraná no Brasil. O estudo contempla a avaliação do potencial CBM, através de: análise estratigráfica e geológica; execução de uma sondagem-teste para determinação de gás natural associado com as camadas de carvão; realização de um modelamento geológico 3D para identificar áreas para exploração; medidas do volume de carvão e do teor de gás metano associado com as camadas de carvão. A análise estratigráfica seqüencial realizada identificou seis paraseqüências, com o desenvolvimento dos carvões mais importantes na paraseqüência 2 e 3 , base de um trato de sistemas transgressivos. As zonas de carvão foram correlacionadas com base na distribuição das paraseqüências, e métodos petrográficos foram usados para determinar rank e composição dos carvões. Os estudos geológicos envolveram a locação de falhas e levantamentos gravimétricos para mapeamento de ocorrências de diabásio. O conteúdo de gás associado com as camadas de carvão varia de $0,32-2,18 \mathrm{~m}^{3} / \mathrm{t}$ de carvão e para a área de modelagem $3 \mathrm{D}$ foi calculado um conteúdo de metano da ordem de 5,5 bilhões de metros cúbicos.
\end{abstract}

Palavras-chave: Bacia do Paraná, metano, CBM, carvão, energia.

\begin{abstract}
The Coalbed Methane (CBM) potential of the Santa Terezinha coalfield - 3D modeling and evaluation of exploration well CBM001-ST-RS. The objectives of the present study were to evaluate the coalbed methane (CBM) potential of the Santa Terezinha coalfields of the Paraná Basin, Brazil. The evaluation of the CBM potential is based on: stratigraphic and geological analyses, the drilling of a test well to determine the volume of gas associated with the coal seams and to develop a 3D geological model to assess coal volume and associated gas volumes. The stratigraphical analysis identified 6 para-sequences, with best coal development in parasequences 2 and 3 associated with a transgessive systems tract. The coal zones were correlated based on the sequence stratigraphic interpretation, and petrographic methods were applied to determine coal rank and composition. Geological studies involved the determination of the fault system of the coalfields and mapping of the diabase distribution associated with the coal-bearing strata. The gas content associated with the coal seams ranges from $0.32-2.18 \mathrm{~m}^{3} / \mathrm{t}$ of coal, and based on the 3D geological model a total of 5.5 billion $\mathrm{m}^{3}$ methane was estimated to be associated with the coal seams in the area investigated.
\end{abstract}

Keywords: Paraná Basin, methane, CBM, coal, energy.

INTRODUÇÃOO O recurso coal bed methane (CBM) trapeado dentro do sistema de poros de camadas de carvão, pode alcançar $250 \times 10^{12} \mathrm{~m}^{3}$ (Murray 1996) e é maior do que as reservas coletivas de todos os campos convencionais de gás conhecidas no mundo. Até o presente, o metano do carvão em camada é produzido comercialmente nos Estados Unidos e no Canadá, enquanto que em muitos outros países (e.g., China, Índia, Austrália, Polônia, Alemanha), as bacias de carvão são avaliadas pelo seu potencial de CBM.

No Brasil, a principal e de longe mais importante sucessão sedimentar portadora de carvão ocorre na Bacia do Paraná (Fig. 1), que é uma vasta bacia intracratônica sul-americana, desenvolvida completamente sobre crosta continental, e preenchida por rochas sedimentares e vulcânicas, cujas idades variam entre o Ordoviciano e o Cretáceo (Zalãn et al. 1990, Milani 2000). As camadas de carvão em questão pertencem à Formação Rio Bonito (Fig. 1), que teve sua gênese durante o Eopermiano da Bacia do Paraná em um paleo-ambiente parálico. A Formação Rio Bonito não é aflorante na região de estudo, estando a profundidades que variam de 400 a $1000 \mathrm{~m}$, algumas partes assentada diretamente sobre o embasamento cristalino.

A área de CBM estudada no presente projeto está localizada na região nordeste do estado do Rio Grande do Sul (Fig. 1), na Jazida Santa Terezinha, que parecem ter o maior potencial CBM em carvões da Bacia do Paraná conforme estudos preliminares (Ka1kreuth \& Holz 2000, Kalkreuth et al. 2003) baseado no grau de carbonificação (betuminoso alto volátil C/A), distribuição do carvão (espessura cumulativa ate $>9$ $\mathrm{m}$, um total de 18 camadas de carvão individuais de até $3,0 \mathrm{~m}$ em espessura) e variação na profundidade das camadas (400-1000 m). Resultados de medidas da refletância da vitrinita em mais de 100 amostras de 

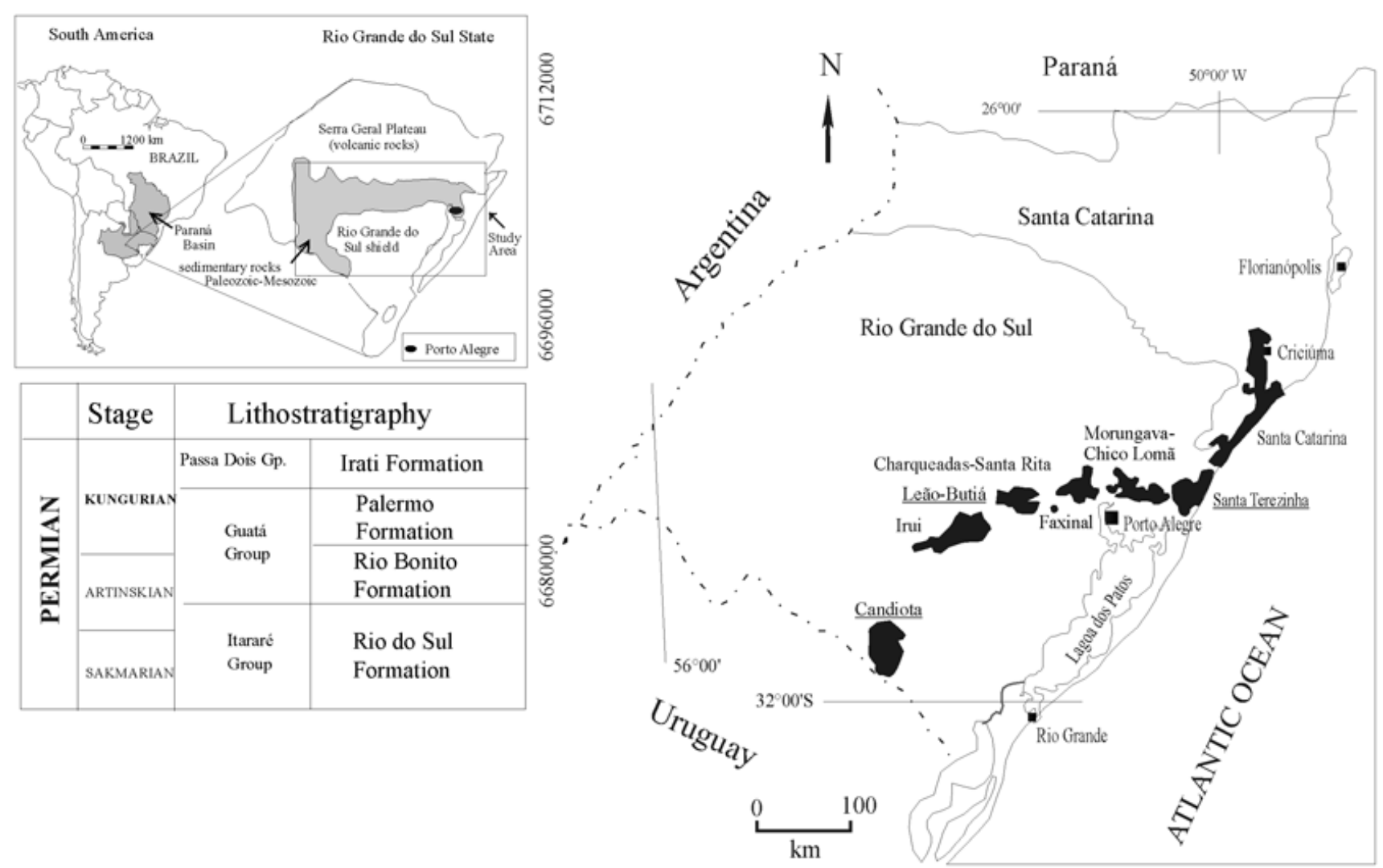

Figura 1 - Mapa da localização da Bacia do Paraná na América do Sul e depósitos de carvão no Rio Grande do Sul e Santa Catarina. O carvão ocorre na Formação Permiano Rio Bonito. A área estudada localiza-se na jazida de Santa Terezinha.

testemunhos (Kern 2002) mostraram uma variação de $0,53-0,99 \%$ Rrandom (carvão betuminoso alto volátil C/A). Localmente, intrusões de diabásio tem alterado o grau de carbonificação dos carvões, para antracito, com refletâncias de até 5,46\%.

O estudo desenvolvido contemplou um estudo avaliativo do potencial CBM, através de:

- análise estratigráfica e geológica;

- realização de um modelamento geológico 3D para identificar áreas para exploração;

- execução de uma sondagem-teste de CBM com a recuperação das camadas de carvão, seguidas de medidas de desorção de metano;

- estimativa de gás natural (CBM) contido na jazida de Santa Terezinha baseado no volume de carvão determinado pela modelagem $3 \mathrm{D}$ e o teor de gás metano associado com as camadas de carvão, determinado pelas medidas do volume de desorção de gás das amostras de carvão coletadas do furo de sondagem.

MODELAGEM 3D O principal objetivo da modelagem geológica é qualificar e quantificar a distribuição espacial em 3 dimensões das litologias da jazida de Santa Teresinha. Com isso será possível calcular os volumes das camadas de carvão existentes e avaliar a sua distribuição na estratigrafia da área de estudo.

A área escolhida para a modelagem física das camadas de carvão (Fig. 2) abrange cerca $1600 \mathrm{~km}^{2}$ e está limitada pelas coordenadas UTM E 560000 600000 , e N 6670000 - 6710000. Esta área foi escolhida devido ao fato de que contém camadas de carvão que variam de decimetros a métricas $(0,3$ a $2 \mathrm{~m})$ podendo alcançar espessuras superiores a 3 metros, e se encontram em profundidades entre 400 e 1000 metros, o que potencializa a geração termogênica de metano. Outro fator importante para a escolha da área é o bom conhecimento faciológico, deposicional e estratigráfico, bem como estudos geoquímicos. A região representa a área de modelagem com alta resolução no modelo final, devido à boa malha de poços (35) com um bom distanciamento entre eles (entre 5 e $10 \mathrm{~km}$ em média). A área encontra-se na Planície Costeira e compreende uma faixa de cerca de $20 \mathrm{~km}$ de largura a partir da costa por cerca de $45 \mathrm{~km}$ de comprimento (Fig. 2), com sentido nordeste.

A base de dados para o presente trabalho consiste basicamente de perfis descritivos de furos de sondagem, resultantes da intensa pesquisa para a caracterização do potencial carbonífero do estado do Rio Grande do Sul executada pela antiga Companhia de Pesquisa de Recursos Minerais (CPRM), atual Serviço Geológico Brasileiro, na década de setenta e oitenta. A campanha de pesquisa inclui furos de sondagem verticais com recuperação total. Cada furo de sondagem 


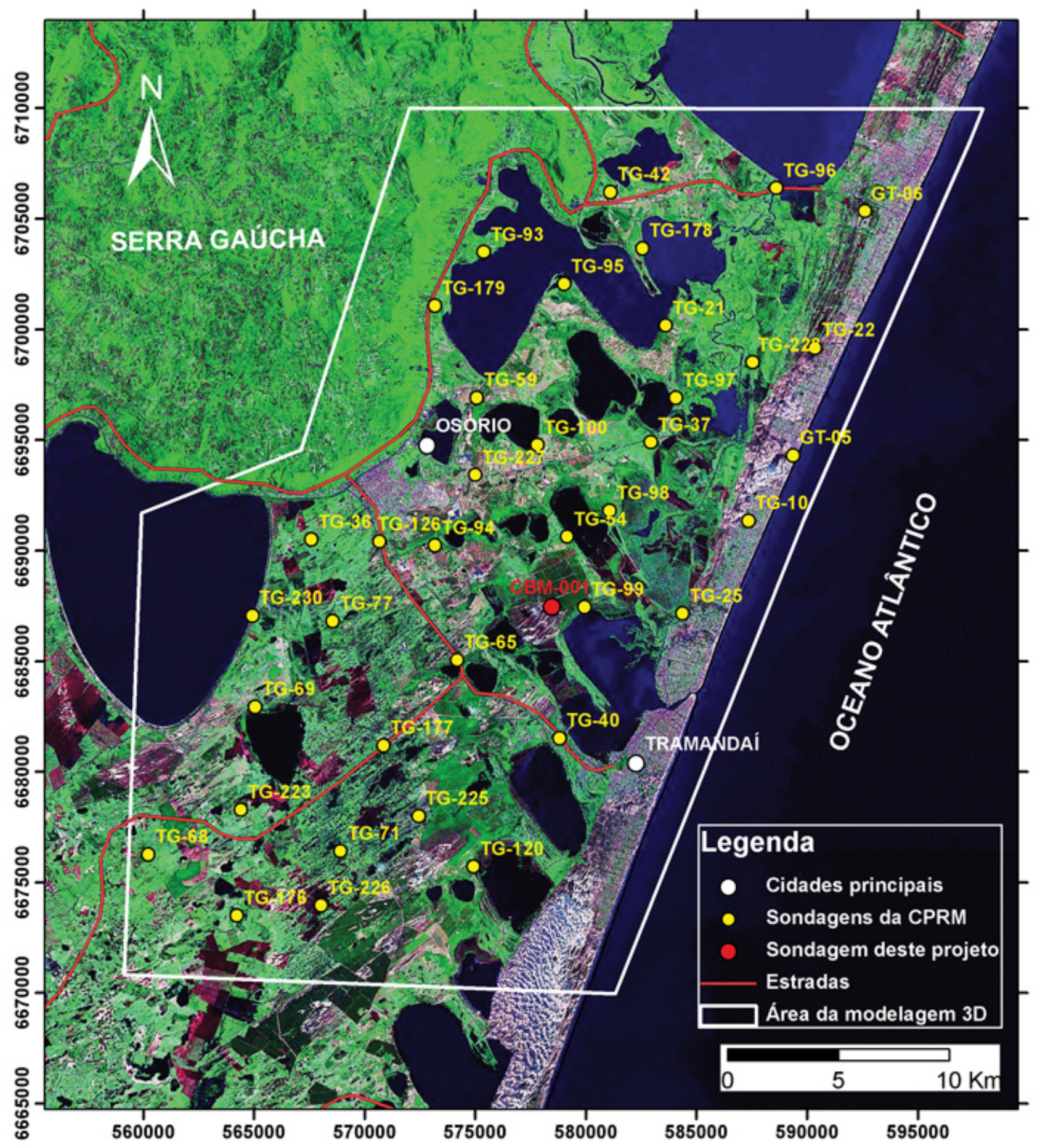

Figura 2 - Modelo de elevação digital de terreno mostrando a localização da área de modelagem e dos poços utilizados. O polígono branco identifica a área que foi modelada. O poço em vermelho é a sondagem realizada neste projeto denominada de CBM 001 ST/RS.

acompanha um perfil descritivo contendo os dados gerais do projeto e do poço, bem como as descrições litológicas feitas durante a campanha de perfuração.

O reconhecimento das principais zonas de falhas foi baseado em um mapa estrutural elaborado pela CPRM. O mapa foi incorporado à modelagem, devidamente georreferenciado, servindo de base para delimitação das falhas, obtendo-se como produto final a divisão de blocos estruturais do embasamento.
Os procedimentos necessários para construção de um modelo geológico 3D passam por 3 etapas principais (Fig. 3): a entrada de dados (input), o desenvolvimento e a saída dos dados (output) onde se obtém o produto final da modelagem.

ANÁLISE GRAVIMÉTRICA O estudo gravimétrico, integrado à análise de dados extraídos de perfis descritivos de furos de sondagem realizados na região, 


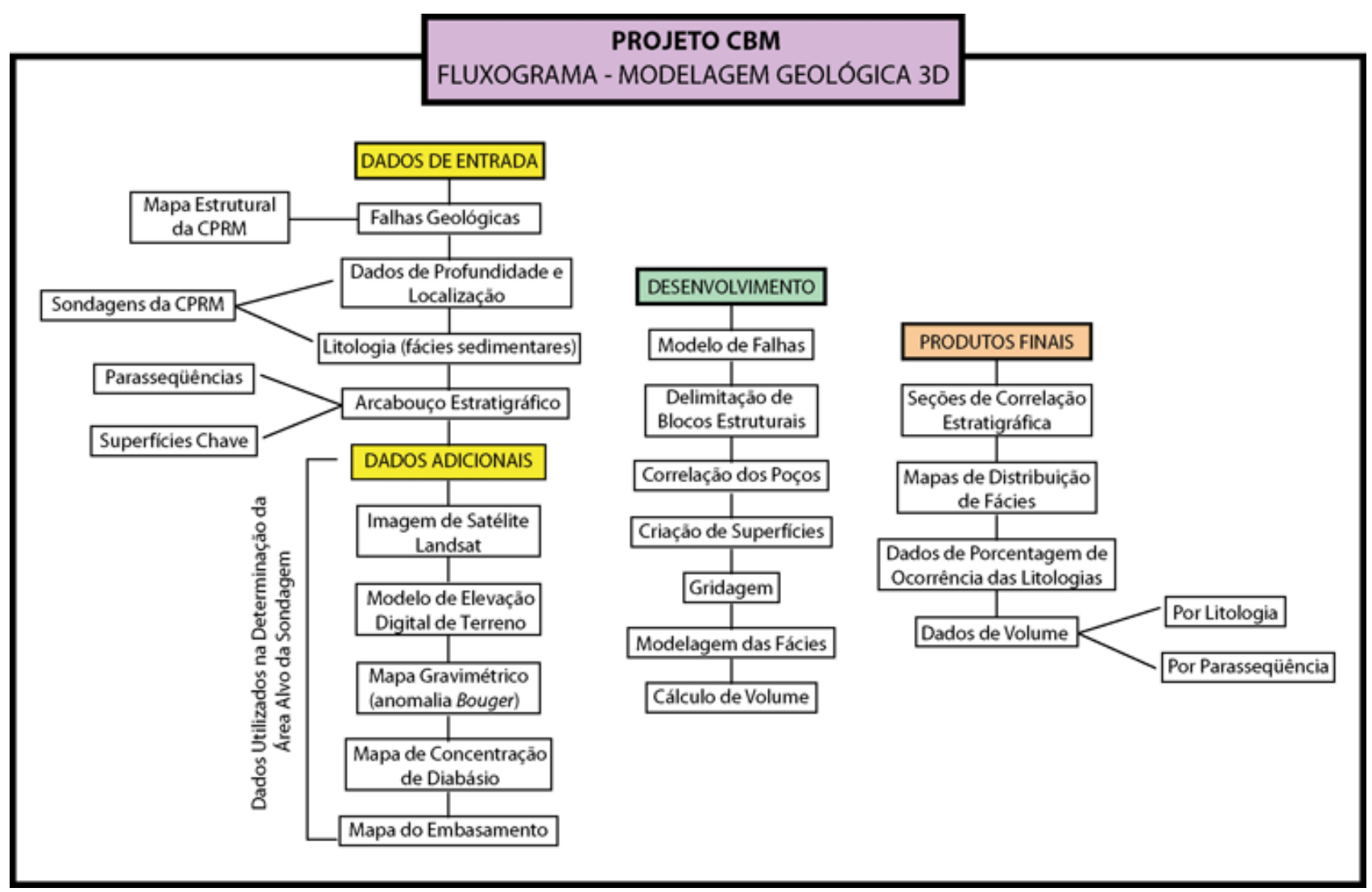

Figura 3 - Fluxograma das principais etapas da estruturação da modelagem geológica.

foi utilizado para se efetuar um reconhecimento de estruturas não aflorantes devido ao domínio de coberturas sedimentares recentes na paisagem da área de interesse, principalmente para caracterizar a presença e geometria de diques e soleiras de rochas hipabissais que podem comprometer a qualidade do reservatório para o armazenamento do gás CBM.

POÇO DE EXPLORAÇÃO CBM 001-ST-RS Baseado nos resultados do modelamento 3D e estudos anteriores da distribuição do rank do carvão (Kalkreuth et al. 2003), acessibilidade e disponibilidade de água para a perfuração, o local do furo de sondagem CBM 001_STRS foi definido entre Tramandaí e Osório, litoral norte do Rio Grande do Sul (Fig. 2), com as seguintes coordenadas UTM E578466, N6687463. Poços próximos de exploração de carvão da CPRM como, por exemplo o TG-99 (Fig. 2) indicavam perfurar o intervalo de carvão na profundidade entre 584-618m com uma espessura de carvão cumulativo perto de $9,00 \mathrm{~m}$, e espessura das camadas individuais de carvão variando de poucos centímetros até um máximo de 2,60 m. Prevendo-se que o rank do carvão fosse betuminoso alto-volátil, com a reflectância da vitrinita entre $0,80-0,90 \%$ Rrandom.

Para fazer a perfuração a GEOSOL LTDA foi contratada, que utilizou técnicas de wireline para retirar os testemunhos com um diâmetro de 47,6 mm (NQ). A técnica wireline é preferida para furos do tipo CBM em relação à tecnicas convencionais, pois permite a re- tirada rápida do testemunho (no nosso caso, numa média de 6 minutos de uma profundidade de $600 \mathrm{~m}$ de profundidade até a superfície) e assim minimiza da perda do gás durante a retirada do testemunho.

O tempo de perfuração previsto para coletar as camadas de carvão foi de 3 semanas, mas duraram quase 3 meses (17.01 - 09.04.2007), devido a diversas razões como falha de equipamento, excesso de chuvas e problemas de cimentação do poço devido a uma espessa camada de areias inconsolidades acima do intervalo de carvão.

\section{MÉTODOS ANALÍTICOS}

Análise gravimétrica Para a o levantamento gravimétrico utilizou-se um gravimetro SCINTREX G-3, um GPS Garmin MAP 76S com altímetro barométrico, para se obter a localização e altitude exata dos pontos onde foram coletados os dados de gravimetria.

\section{Análise de gás natural (metano)}

LABORATORIO MÓVEL Para uma correta avaliação da quantidade de gás metano contido nos carvões, estes devem ser coletadas durante a sondagem através uma retirada rápida usando a metodologia wireline core retrieval e em seguinte armazenamento imediato em cilindros especiais, sob condições ambientais controladas (temperatura, pressão) para poder avaliar corretamente a desorção de gás por peso de carvão $\left(\mathrm{cm}^{3} / \mathrm{g}\right.$ ou $\left.\mathrm{m}^{3} / \mathrm{t}\right)$. Para tanto, faz-se necessário um laboratório móvel 
para ser levado para o sítio de execução da sondagem. O principal equipamento do laboratório móvel é uma caixa que possui 32 cilindros (Fig. 4), cada um de $36 \mathrm{~cm}$ de comprimento, com uma capacidade total de analisar 11,52 m de carvão no mesmo tempo. A temperatura da caixa e controlado para simular o nível da temperatura do reservatório durante o processo de desorção. Baseado na bottom-hole temperatura da área e a temperatura média do ano um gradiente geotérmico de $2,9^{\circ} \mathrm{C} / 100 \mathrm{~m}$ foi determinado, resultando em uma temperatura de $36{ }^{\circ} \mathrm{C}$ na profundidade de $600 \mathrm{~m}$ do poço CBM 001-ST-RS.

AMOSTRAGEM DE CARVÃO As amostras de todos os intervalos de camadas de carvão encontradas foram selecionadas, cortadas em intervalos de $36 \mathrm{~cm}$ e colocadas em 24 cilindros de PVC com tampa de alumínio que foram fechados imediatamente à sua colocação. Antes do fechamento de cada cilindro estes foram pesados vazios e com conteúdo de carvão para ver a quantidade e o peso do material estocado. Além disso, cada cilindro contendo o carvão amostrado após seu fechamento teve o oxigênio retirado por meio da injeção de um gás inerte (Argônio) para não oxidar o material amostrado e acondicionado no recipiente.

Todo o processo de coleta de amostras foi feito o mais rápido possível, afim de não se perder o metano contido nas camadas e leitos de carvão amostrados. A retirada da amostra da profundidade de $600 \mathrm{~m}$ até a superfície durou em torno de 6 minutos. Já o tempo percorrido para armazenar as amostras dentro de cada cilindro também foi todo cronometrado e levou em torno de 6 a 10 minutos. Estes intervalos de tempo foram registrados em planilhas de dados e usados para estimar o volume de gás perdido durante a retirada e armazenamento da amostra.

MEDIDAS DE GÁS NATURAL O conteúdo total de metano nas camadas de carvão consiste em três componentes: volume de desorção de gás medido, volume de gás perdido e volume de gás residual. $\mathrm{O}$ volume de gás medido é obtido através de medições periódicas do volume de gás liberado (Fig. 5), com medições iniciais realizadas em intervalos entre 5 a 10 minutos, enquanto que, ao final do experimento, as medições eram realizadas a cada dois dias. Devido ao fato do peso da amostra ser conhecido ( no nosso caso, a amostra era pesada apenas
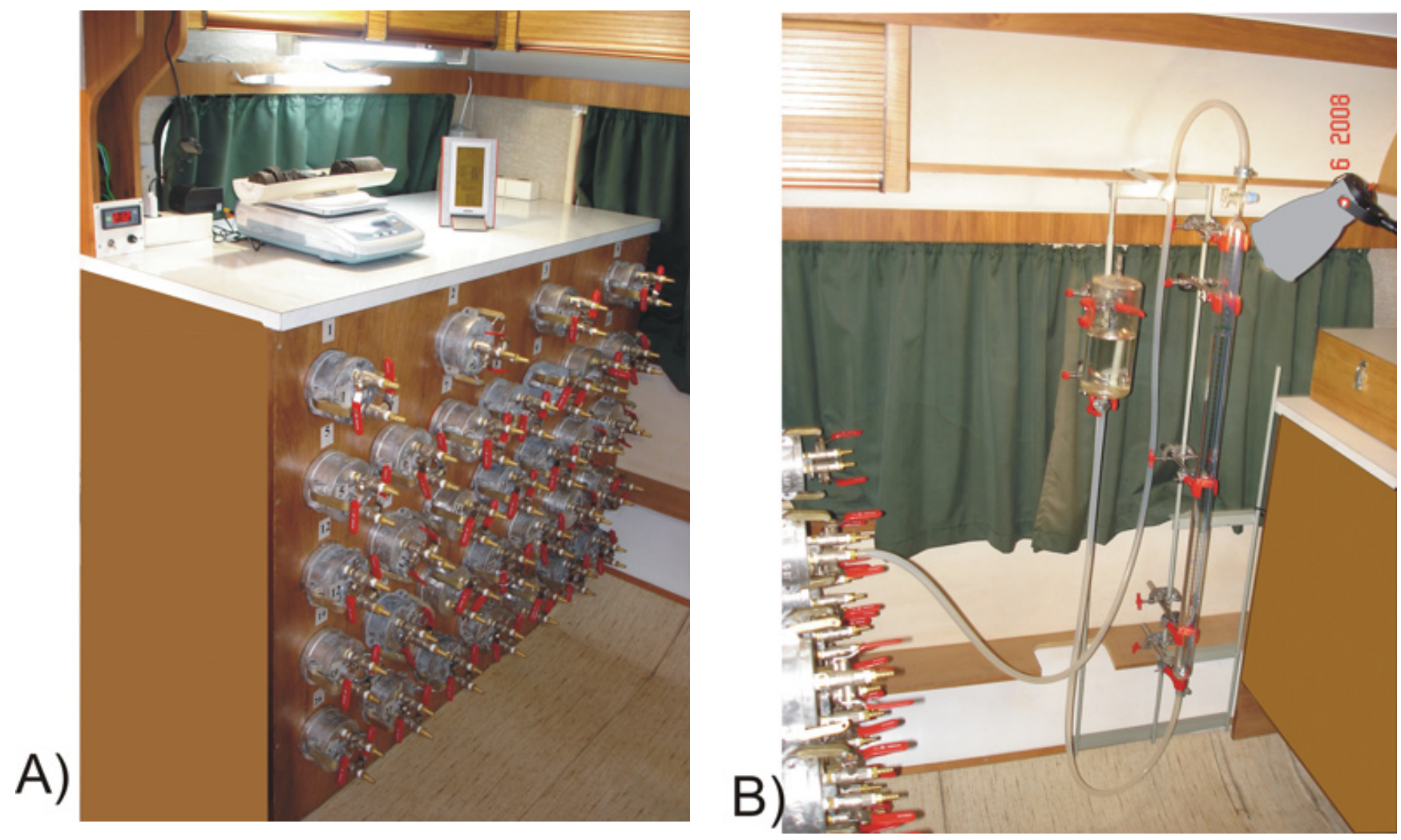

Figura 4A - Bancada com termopar, balança de precisão, mini estação metereológica e 32 cilindros para o armazenamento das amostras de carvão, com capacidade máxima de estocagem de $11,52 \mathrm{~m}$ de testemunhos. Cada cilindro possui capacidade de armazenar até $36 \mathrm{~cm}$ de carvão. Os cilindros são utilizados para a medida do gás metano em desorção das amostras de carvão coletadas.

Figura $4 B$ - Coluna de vidro graduada $\left(\mathrm{mm}^{3}\right)$ e reservatório de água em vidro borossilicatado utilizado para a medição do volume de gás metano em desorção dos cilindros com amostras de carvão coletadas. 
A

CBM001-ST-RS

Cilindro 11

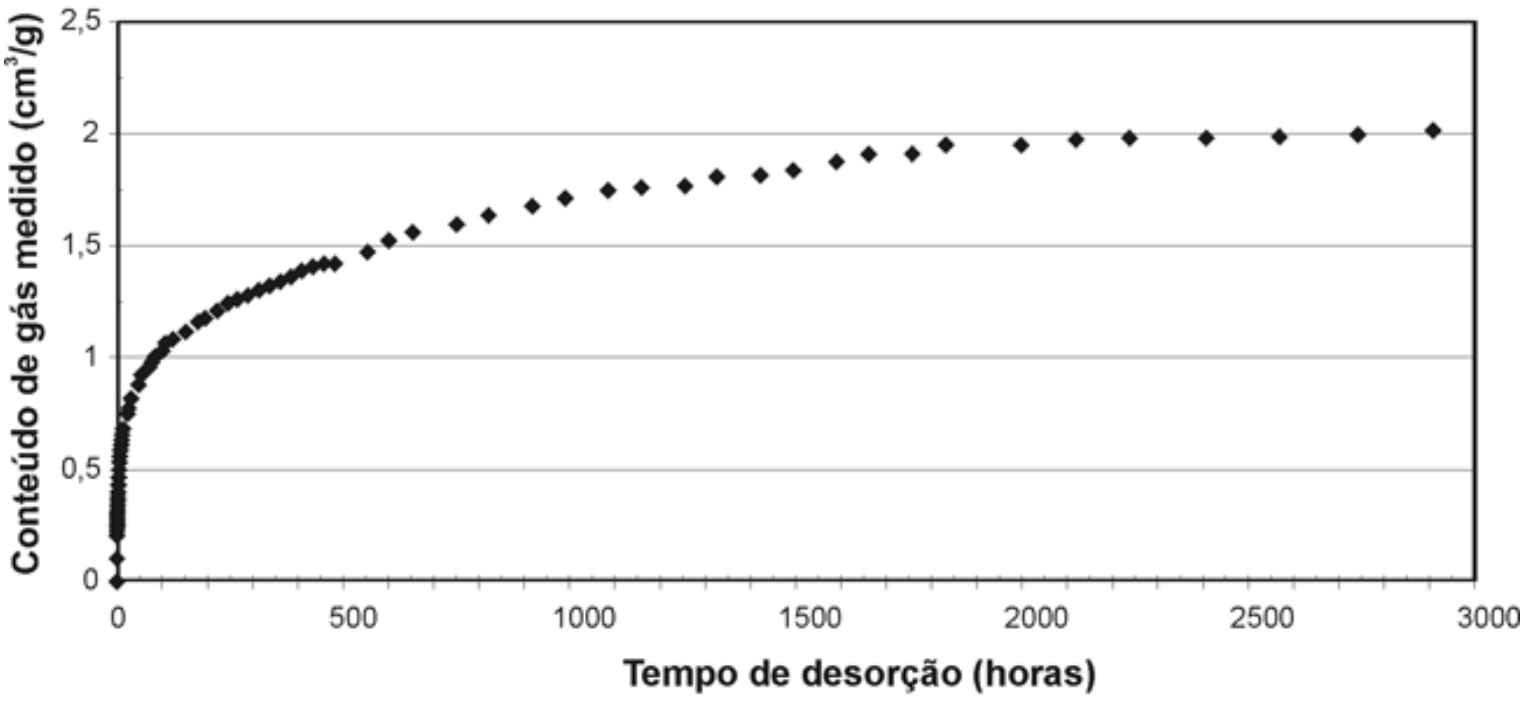

B

Cilindro 11 - Gás perdido estimado

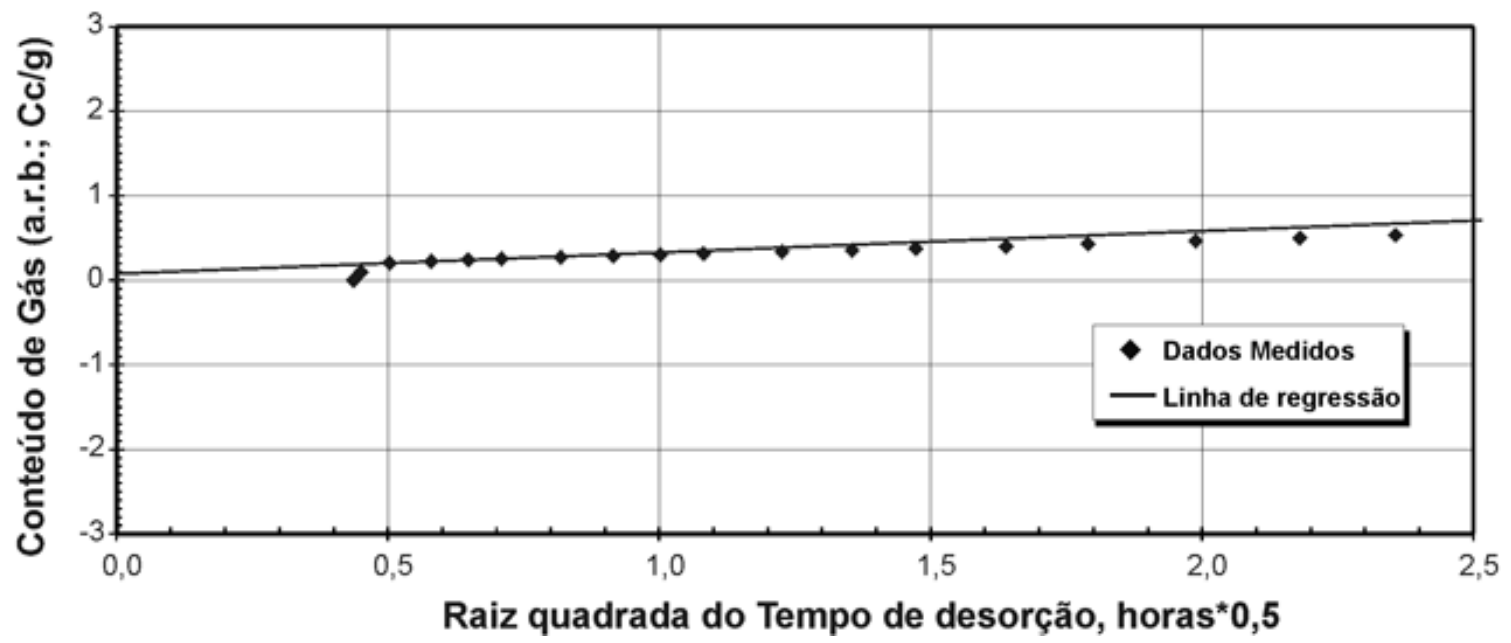

Figura 5 - Exemplo de medidas de gás de desorção (topo) e estimativa de gás perdido (base).

depois das medições terminadas), o volume de gás cumulativo medido é expresso em $\mathrm{cm}^{3} / \mathrm{g}$ ou $\mathrm{m}^{3} / \mathrm{t}$ de carvão.

O volume de gás perdido é estimado através da plotagem do volume de desorção do gás cumulativo versus a raiz quadrada do tempo de desorção com a linha de regressão projetada para o tempo zero, quando iniciou-se a desorção do gás presente no carvão.

$\mathrm{O}$ volume de gás redisual é definido como a quantidade de gás ainda restante no carvão após o final da desorção. Na maioria dos casos existe em pequena quantidade do gás residual e pode ser determinado através do esmagamento do carvão num sistema fechado, seguido por medidas do gás liberado. Nesse estudo, o volume de gás residual foi estimado baseando-se em estudos de Gentzis and Bolen (2008), os quais descreveram o volume de gás residual como não ultrapassando $4,5 \%$ do conteúdo de gás total.
COMPOSIÇÃO DE GÁS NATURAL E ISOTOPOS DO $C A R B O N O$ Algumas amostras foram selecionadas e analizadas em termos da composição do gás (metano, etano, propano, butano) e gases não-hidrocarbonetos $\left(\mathrm{CO}_{2}\right.$ e $\left.\mathrm{N}_{2}\right)$ utilizando um Cromatógrafo Gasoso no Laboratório da Petrobrás/CENPES.

Isótopos de carbono estável foram identificados através de um Espectrômetro de Massa no Laboratório da Petrobrás/ CENPES.

Análises químicas de carvão

ANÁLISE IMEDIATA, ANÁLISE DE ENXOFRE E PODER CALORIFICO Análise imediata compõe-se de quatro diferentes tipos de análises: \% de Umidade (ASTM D3173-87, \% de Cinzas (ASTM D3174), \% de Matéria Volátil (ASTM D3175). Carbono Fixo é um valor calculado pela soma dos percentuais de umidade, 
cinza e matéria volátil, subtraído de 100 .

O enxofre no carvão é determinado utilizando combustão em alta temperatura através de um detector de absorção infravermelho (IR), segundo ASTM D 4239 (1991). O instrumental utilizado é o modelo SC132 da LECO Corporation.

O Poder Calorífico é determinado em uma Bomba Adiabática Calorimétrica e apresentar o calor (Kcal $\mathrm{kg}$ ) produzido pela combustão da materia orgânica.

\section{Análises petrologicas de carvão}

REFLECTANNCIA DA VITRINITA E ANÁLISE DE MACERAIS E MINERAIS A determinação do poder refletor da vitrinita foi realizada através da medida em partículas de colotelinitas em posição espacial aleatória dentro das secções polidas de grão, seguindo a norma internacional ISO 7404/5 (1984).

As análises de macerais foram realizadas de acordo com a norma internacional ISO 7404-3 (1984). A contagem foi realizada através de um contador de pontos semi-automático, no caso, SWIFT F 415.

\section{RESULTADOS}

Interpretação da seqüência estratigráfica do intervalo de carvão e correlação das camadas de carvão $O$ intervalo portador de carvão corresponde a Formação Rio Bonito, que ocorre no Estado com espessura média de $70 \mathrm{~m}$, podendo alcançar $120 \mathrm{~m}$ em algumas áreas. A idade é correspondente ao Sakmariano-Artinskiano (Eo-Permiano), com base em informações palinológicas e paleobotânicas.

Sob a óptica da estratigrafia de seqüências, o intervalo portador de carvão encerra-se na Seqüência II de Holz et al. (2006). No trato de sistemas de nível baixo dessa seqüência ocorrem apenas camadas finas e descontínuas de carvão, inaproveitáveis economicamente. Os carvões mais importantes do ponto de vista do potencial de CBM ocorrem no trato transgressivo, composto por quatro paraseqüências da ordem de dez a quinze metros de espessura. Essas paraseqüências serviram de base para a correlação das camadas de carvão e para orientação do modelo 3D desenvolvido. A estratigrafia de seqüências se mostrou uma ferramenta mais adequada e segura de correlacionar as camadas de carvão, principalmente considerando que muitas apresentam pinchouts e splits múltiplos que dificultam a correlação na maneira litoestratigráfica tradicional. Trabalhando-se com as superfícies de inundação das paraseqüencias como ferramenta analítica, na área de estudo foram reconhecidas as principais superfícies limítrofes como LS, SIM e ST, permitindo a interpretação das seqüências deposicionais, seus tratos de sistemas e a definição do conjunto de parasseqüências de acordo com o padrão de empilhamento das mesmas, e o agrupamento das camadas de carvão nas diferentes paraseqüências foi realizado. Um resumo desse arcabouço estratigráfico pode ser encontrado na figura 6 .

Análise gravimétrica $\mathrm{O}$ estudo gravimétrico teve por objetivo caracterizar a presença e geometria de diques e soleiras de rochas hipabissais que podem comprometer o potencial de CBM nas camadas afetadas por essas intrusões.

Para a o levantamento gravimétrico utilizou-se um gravimetro SCINTREX G-3, pertencente ao Instituto de Geociências da UFRGS, um GPS Garmin MAP $76 \mathrm{~S}$ com altímetro barométrico, para se obter a localização e altitude exata dos pontos de aqusição dos dados de gravimetria.

Os mapas de anomalias gravimétricas obtidos foram interpretados e comparados com mapas de concentrações de determinadas litologias, assim como as principais estruturas verificadas em superfície na região.

O mapa de anomalia bouguer da região em es-

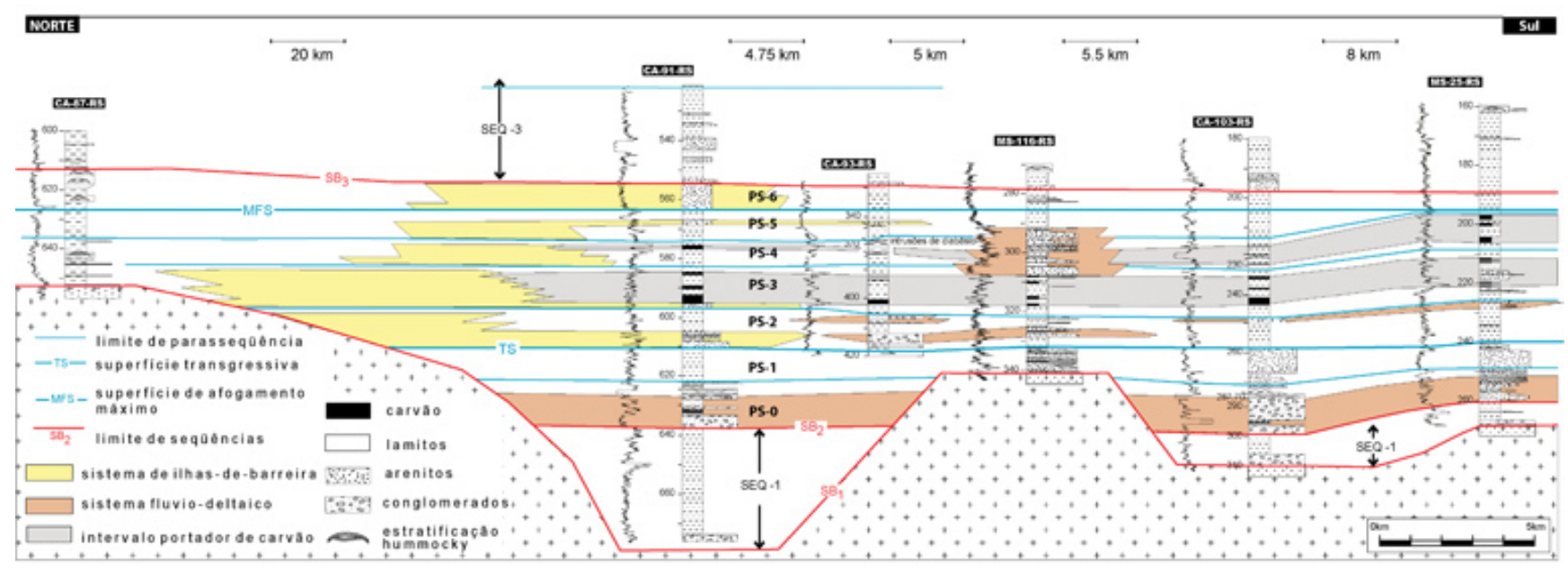

Figura 6 - Arcabouço estratigráfico com as paraseqüências da sucessão portadora de carvão. Notar que as principais camadas de carvão encontram-se no trato transgressivo, especialmente nas paraseqüencias 2 e 3. Datum para correlação foi a superfície de máxima inundação da seqüência deposicional. A espessura das paraseqüências e o teor de carvão de cada uma destas forma a base de dados para a modelagem 3D da jazida. 
tudo revelou três áreas com relevos gravimétricos distintos, com uma diminuição nos valores das anomalias de norte para sul, o que indica uma diminuição da densidade das rochas nesta direção; concluindo-se que o embasamento cristalino da bacia na região estudada se torna mais profundo à norte.

Aos mapas de superfície gravimétrica, também se fez comparações com mapas de isópacas de diabásios e de carvões da seqüencia 2, produzidos no programa de computador Surfer 8, com base nos dados extraídos das descrições de perfil litológico da CPRM .

Para visualizar a distribuição dessas duas litologias e a respectiva resposta gravimétrica, ao mapa de diabásio total foi sobrepostos o mapa de sinal analítico (Fig. 7A).

Em relação às camadas de carvão foi aplicado à mesma metodologia, sobrepondo-se os mapa de isópacas de carvão com o mapa de anomalia bouguer residual (Fig. 7B).

O mapa de contorno de concentração de diabásio da seqüencia 2 , a maior parte desses corpos tem suas maiores espessuras fora da área de maior concentração de carvão. Maiores concentrações destes corpos dentro da formação se localizam no nordeste da área e em parte no centro-oeste.

Em relação ao potencial da área para prospecção de CBM pode-se concluir que na área nordeste da região, onde se concentram algumas camadas de carvão consideráveis, também há uma grande concentração de corpos de diabásio, o que torna essa área um alvo pouco confiável.

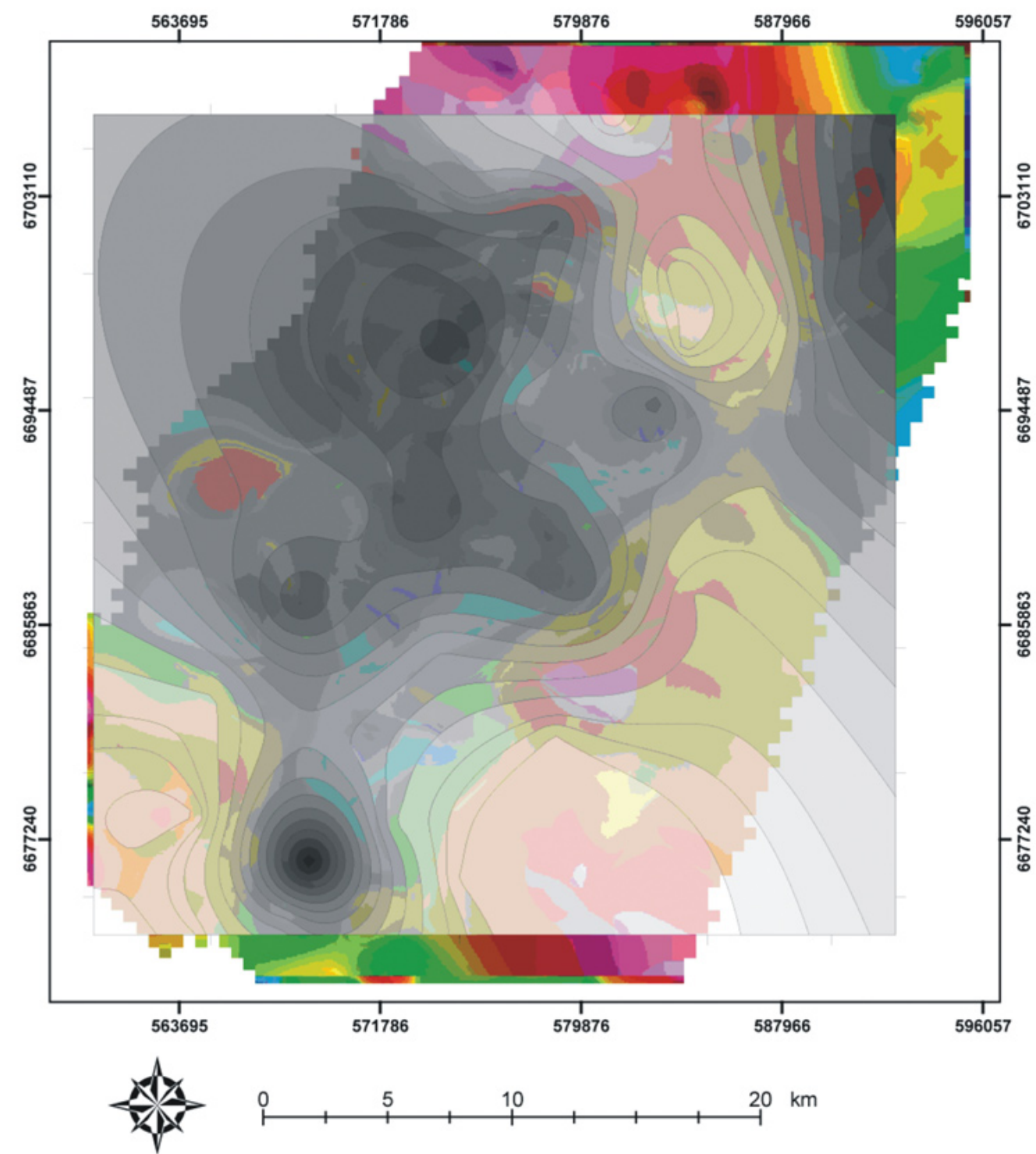

Figura 7A - Sobreposição de mapa de contorno das concentrações de diabásio sobre mapa de amplitude do sinal analítico de anomalia bouguer. Há uma grande correspondência entre os valores de maior concentração do mapa de contorno e regiões de maiores valores de anomalia. Esta figura indica que há maiores concentrações de corpos de diabásio nas porções oeste e sudoeste da região em estudo. 
Na porção centro-oeste, onde existe a maior concentração deste carvão, há também grandes concentrações de diabásio, porém não inseridos ou intercaladas nas camadas carbonosas, o que a princípio não afetaria o potencial deste bloco dentro da região de estudo.

Assim sendo, essa é a área mais aconselhável para explotação de CBM.

Modelagem volumétrica 3D das camadas de carvão CORRELAÇÃO DE POÇOS E CRIAÇÃO DE SUPERFÍCIES O software Petrel possui módulos para tratar dados de poço, bem como representá-los graficamente, facilitando de forma dinâmica e eficiente a correlação estratigráfica. Desta forma, é possível se obter ses- sões estratigráficas com dados de litologia, perfilagens geofísicas e outros atributos

Com o arcabouço estratigráfico determinado foi possível a correlação dos poços, partindo-se do rastreamento das superfícies estratigráficas importantes e o mapeamento das parasseqüências. Cada parasseqüência corresponde a uma unidade estratal que registra uma sedimentação temporalmente correspondente, sendo avaliado em quais intervalos de tempo e em quais áreas se teve a formação de carvão.

Além disso a correlação serve de base para a criação de superfícies tridimensionais (Fig. 8). As superfícies são formadas a partir da extensão do dado pontual em cada poço, utilizando-se também do modelo de fal-

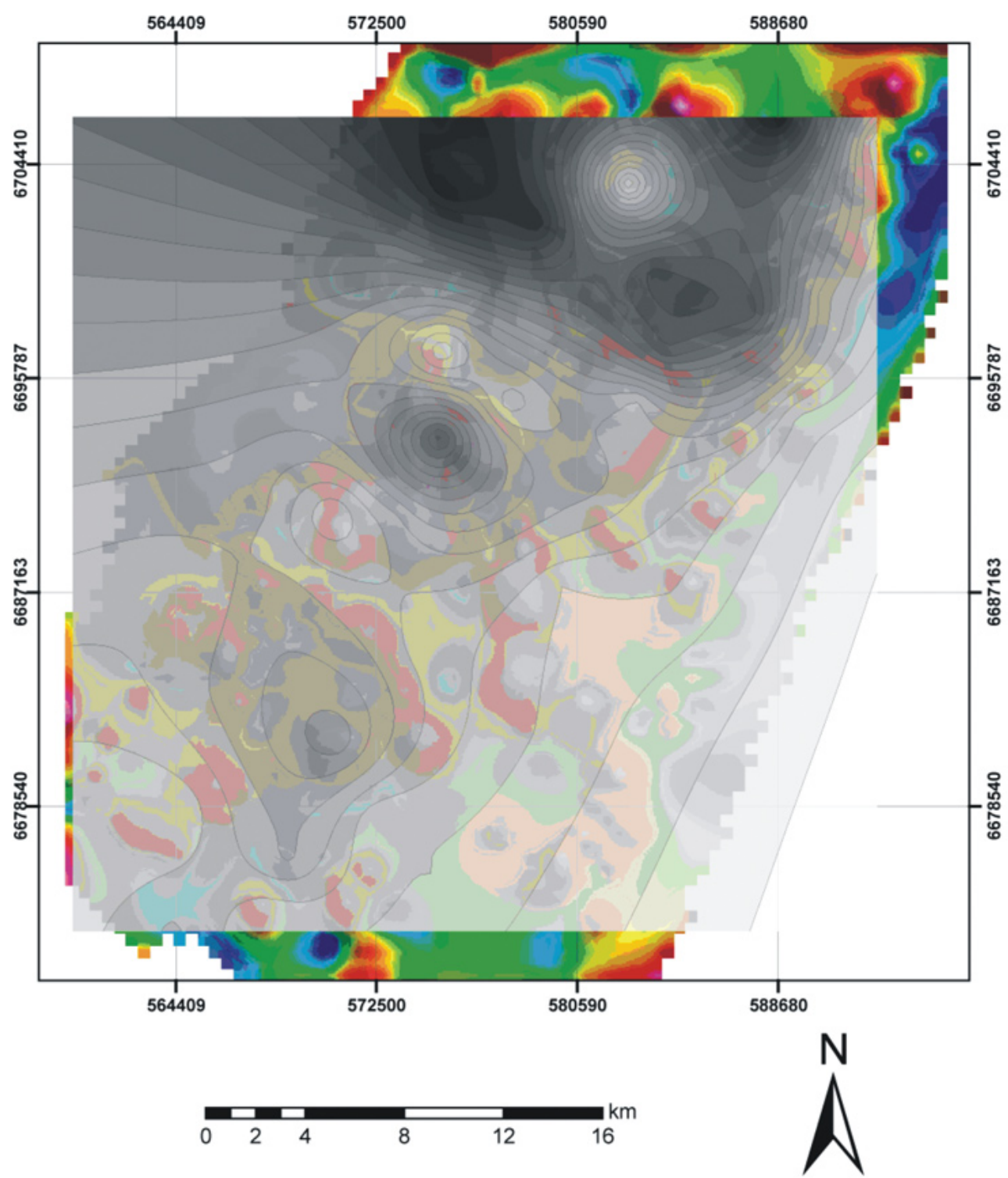

Figura $7 B$ - Sobreposição de mapa de contorno das concentrações de carvão sobre mapa de anomalia bouguer residual. É notória uma correspondência entre as áreas de maior concentração de carvão do mapa de contorno e a porção central do mapa bouguer residual, onde há uma maior concentração de baixos valores de anomalias. Regiões de acúmulo de carvão coincidem com área de baixo gravimétrico. 
has para compartimentá-las. No caso de trabalho foram criadas superfícies representativas da base de cada parasseqüência. Foram mapeadas 6 paraseqüências, das quais apenas da $2^{\circ}$ à $5^{\circ}$ foram utilizadas, já que representam o intervalo das camadas de carvão. A distribuição das litologias na parasequencia 2, que apresentar a major quantidade de carvão e mostrada na figura 9.

DADOS DE VOLUME Ao final de todos da modelagem 3D foi obtido a distribuição das litologias na área de estudo em volume total e também por paraseqüências. De acordo com o modelo 3D, a litologia predominante no estudo é siltito, seguido por arenito, carvão, diabásio e conglomerado. A proporção de carvão é substancialmente mais alta na paraseqüência 2 , com um valor de $171510^{6} \mathrm{~m}^{3}$.

Através de dados da densidade média do carvão na jazida de Santa Terezinha $\left(1,79 \mathrm{~g} / \mathrm{cm}^{3}\right)$ foi feita a conversão para toneladas, chegando-se a um valor total de 5,46 bilhões de toneladas de carvão para a área da modelagem.

Perfil litológico do intervalo do carvão $\mathrm{O}$ intervalo de carvão da Formação Rio Bonito foi encontrado entre 606,35 e 638,22 m de profundidade (Fig.10), com a presença de doze camadas de carvão, apresentando espessuras variando entre $0,16 \mathrm{~m}$ (camada $\mathrm{A}$ ) até $1,77 \mathrm{~m}$ (camada G), e com um espessura de carvão cumulativo de 7,41 m. As camadas de carvão são intercaladas com siltito e, na porção superior algumas camadas de carvão

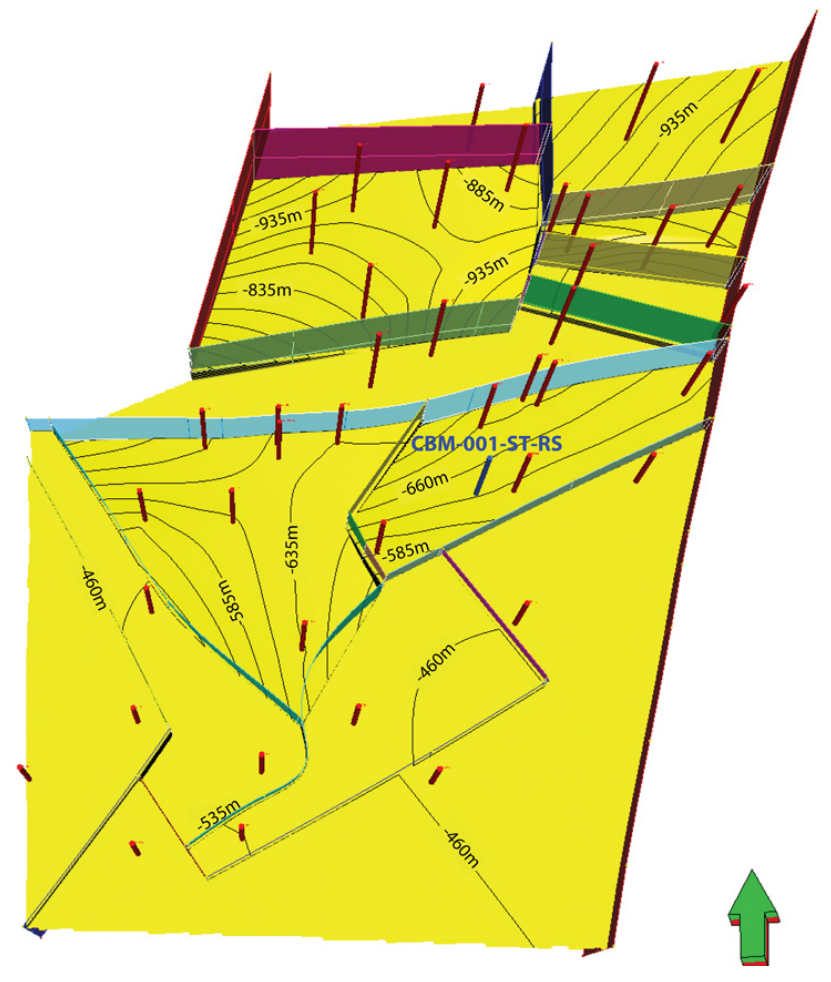

Figura 8 - Exemplo de superficie criada (base da paraseqüencia 2) com base no modelo de falhas, seta verde indica o norte.

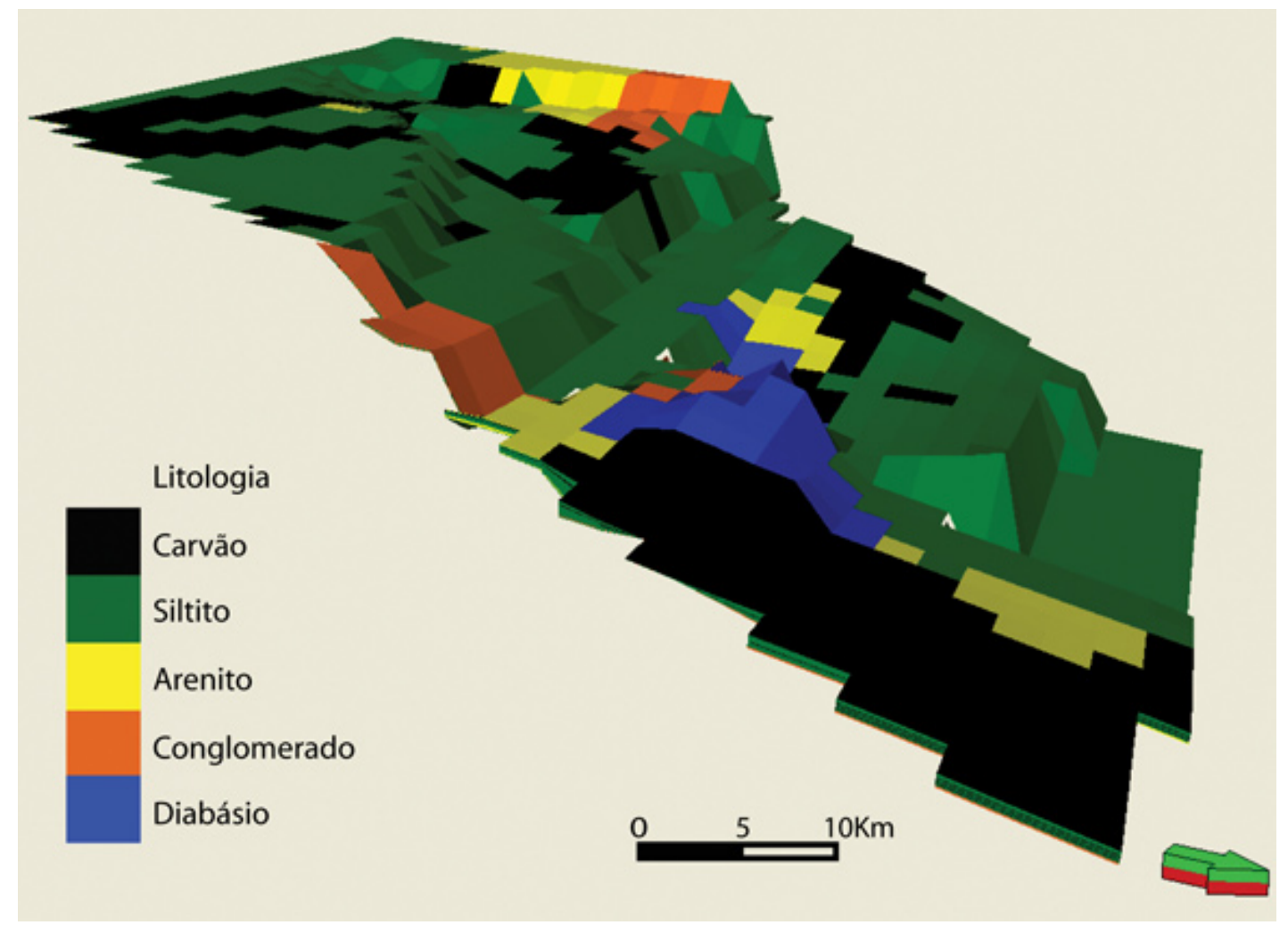

Figura 9 - Distribuição das litologias na parasseqüência 2, esta é a que apresenta a maior quantidade de carvão. Exagero vertical de $5 X$. 
estão em contato com diabásios. Os melhores depósitos de carvão ocorrem nas paraseqüências 2 e 3 , enquanto que nas paraseqüências 4 e 5 as camadas de carvão são caracterizadas por uma menor espessura (Fig. 10). Para os testes de desorção de gás, um total de 24 cilindros foram utilizados (Fig. 10) para armazenar a espessura total de carvão retirada através de técnicas wireline.

\section{Características do carvão}

PETROLOGIA DE CARVÃO As medidas da reflectância da vitrinita indicam um rank de betuminoso alto volátil C/A (Tab. 1) com algumas camadas afetadas por intrusões vulcânicas no topo da sequência (Fig. 10) causando um aumento da reflectância da vitrinita correspondente ao nível de betuminoso médio volátil, betuminoso baixo volátil e semi-antracita (Tab. 1).

A análise dos macerais (Tab. 2 e Fig. 10) indicam a predominância da inertinita, variando de 31,2 Vol\% (base da camada E) até $66,2 \mathrm{Vol} \%$ (topo da camada F). O conteúdo de vitrinita é bastante variável, de 1 Vol\% na camada L3 até $53 \mathrm{Vol} \%$ no topo da camada $\mathrm{H}$. Amostras contendo baixo conteúdo de vitrinita têm em comum os altos conteúdos de inertinita e cinza, sugerindo que a materia orgânica acumulada em condições parcialmente oxidantes favorece a formação de macerais de intertinita como fusinita, semifusinita e inertodetrinita. Conteúdos de liptinita variam de 0 até um máximo de 12 Vol\% numa amostra da Camada G (Tab.
2), e ocorrem principalmente nas formas de esporinita e cutinita.

A matéria mineral identificada microscopicamente varia entre 6,6 à $55,0 \mathrm{Vol} \%$ (Tab. 2) e compreende argila, quartzo, carbonato e pirita.

QUIIMICA DO CARVÃO As camadas mostram enriquecimento das cinzas variando de 28,4 até $92,7 \%$ em peso com o valor médio de $54,00 \%$ em peso e, de acordo com resultados da difratometria de raio $\mathrm{X}$ consiste quase inteiramente de quartzo, caolinita e mica, com menor contribuição de pirita, anquerita, calcita, dolomita, albita e alunita. De acordo com a classificação internacional de camadas de carvão in-situ, camadas de carvão que contêm mais de $50 \%$ de conteúdo de cinza em peso são classificadas como folhelho carbonoso. Aplicando essa classificação todas as camadas das paraseqüências 4 e 5 (Tab. 1), e a maioria das camadas coletadas da paraseqüência 2 são folhelhos carbonosos. Camadas de carvão presentes na paraseqüencia 3 têm em geral relativamente baixos conteúdos de cinza, exceto da base e topo da seqüência.

O conteúdo de matéria volátil varia de 5,0\% em peso na camada L1 caracterizado por um conteúdo alto de cinza até $29,6 \%$ em peso na amostra da camada A (Tab. 2). A matéria volátil recalculada em dry ash-free para amostras tendo menos de $50 \%$ de conteúdo de cinza variam de $32,59-45,01 \%$ em peso e corresponde

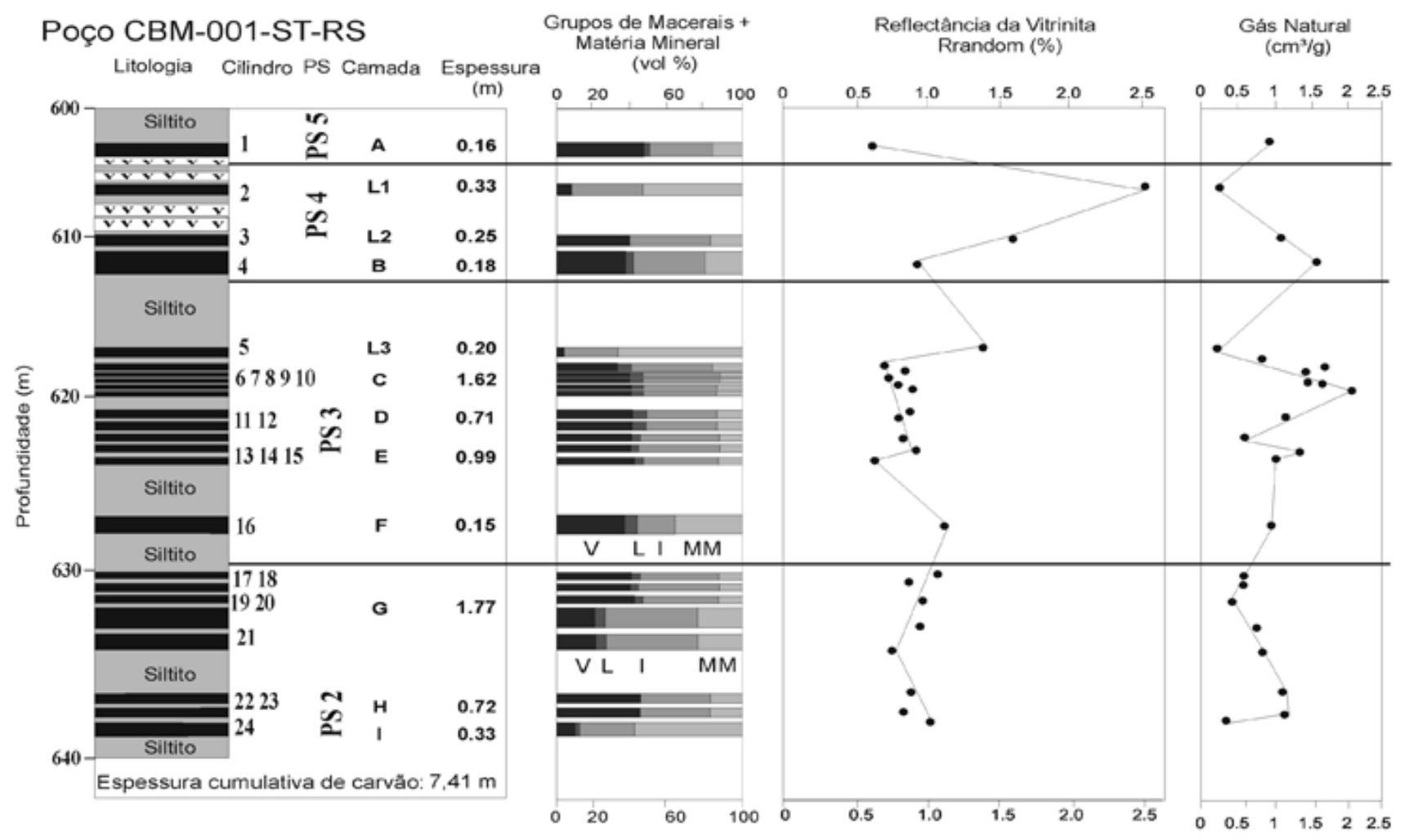

Figura 10 - Distribuição das camadas de carvão no poço CBM001-ST-RS, identificação das amostras, limites de paraseqüencias, espessura das camadas, composição das camadas em termos de grupos de macerais, reflectância da vitrinita e conteúdo total de gás natural. 
Tabela 1 - Identificação do carvão do poço CBM001_-ST-RS, indicando profundidade, paraseqüências, rank do carvão, reflectância da vitrinita, conteúdo de cinza e conteúdo de gás associado com as camadas de carvão.

\begin{tabular}{|c|c|c|c|c|c|c|c|c|c|c|c|}
\hline Cilindros & Camada & $\begin{array}{l}\text { Profundidade } \\
\text { (m) }\end{array}$ & $P S$ & Amostra & Rank & $\begin{array}{c}\text { Rrandom } \\
\text { (\%) }\end{array}$ & $\begin{array}{l}\text { Cinza } \\
(\%, e m \\
\text { peso })\end{array}$ & $\begin{array}{l}\text { Gás-m } \\
(\mathrm{cm} / \mathrm{g})\end{array}$ & $\begin{array}{l}\text { Gás- } p \\
(\mathrm{~cm} / \mathrm{g})\end{array}$ & $\begin{array}{l}\text { Gás-r } \\
(\mathrm{cm} / \mathrm{g})\end{array}$ & $\begin{array}{c}\text { Gás } \\
\text { Total } \\
\left(\mathrm{cm}^{3} / \mathrm{g}\right)\end{array}$ \\
\hline 1 & A & $606,35-606,62$ & PS5 & $07-128$ & Betuminoso Alto Volátil C & 0,65 & 53,64 & 0,89 & 0,03 & 0,04 & 0,96 \\
\hline 2 & L1 & $609,10-609,47$ & PS4 & $07-114$ & Semi-Antracito & 2,61 & 93,13 & 0,37 & 0,00 & 0,01 & 0,38 \\
\hline 3 & L2 & $610,30-610,66$ & PS4 & $07-117 / 118$ & Betuminoso Baixo Vblátil & 1,50 & 73,43 & 0,93 & 0,07 & 0,04 & 1,04 \\
\hline 4 & B & $611,05-611,41$ & PS4 & $07-131$ & Betuminoso Alto Volátil A & 0,88 & 62,17 & 1,45 & 0,04 & 0,06 & 1,55 \\
\hline 5 & L3 & $617,03-617,39$ & PS3 & $07-121$ & Betuminoso Médio Volátil & 1,44 & 83,98 & 0,31 & 0,01 & 0,01 & 0,34 \\
\hline 6 & $\mathrm{C}$ & $618,24-618,60$ & PS3 & $07-151$ & Betuminoso Alto Volátil B & 0,76 & 68,07 & 0,82 & 0,06 & 0,03 & 0,90 \\
\hline 7 & $\mathrm{C}$ & $618,83-619,20$ & PS3 & $07-153$ & Betuminoso Alto Volátil A & 0,82 & 46,39 & 1,55 & 0,07 & 0,06 & 1,69 \\
\hline 8 & $\mathrm{C}$ & $619,20-619,57$ & PS3 & $07-123$ & Betuminoso Alto Volátil A & 0,79 & 35,40 & 1,34 & 0,11 & 0,06 & 1,51 \\
\hline 9 & $\mathrm{C}$ & $619,57-619,93$ & PS3 & $07-155$ & Betuminoso Alto Volátil B & 0,77 & 37,09 & 1,39 & 0,08 & 0,06 & 1,53 \\
\hline \multirow[t]{2}{*}{10} & $\mathrm{C}$ & $619,93-620,30$ & PS3 & $07-160$ & Betuminoso Alto Volátil A & 0,94 & 34,43 & 1,44 & 0,11 & 0,06 & 1,61 \\
\hline & $\mathrm{C}$ total & $618,24-620,30$ & PS3 & & & 0,82 & 43,74 & 1,31 & 0,09 & 0,05 & 1,46 \\
\hline 11 & $\mathrm{D}$ & $620,80-621,17$ & PS3 & $07-166$ & Betuminoso Alto Volátil A & 0,92 & 49,34 & 2,01 & 0,08 & 0,09 & 2,18 \\
\hline \multirow[t]{2}{*}{12} & $\mathrm{D}$ & $621,20-621,56$ & PS3 & $07-162$ & Betuminoso Alto Volátil A & 0,83 & 36,03 & 1,08 & 0,05 & 0,04 & 1,17 \\
\hline & D total & $620,80-621,56$ & PS3 & & & 0,87 & 42,08 & 1,50 & 0,06 & 0,06 & 1,63 \\
\hline 13 & $\mathrm{E}$ & $622,34-622,72$ & PS3 & $07-168$ & Betuminoso Alto Volátil A & 0,93 & 55,45 & 0,49 & 0,01 & 0,02 & 0,53 \\
\hline 14 & $\mathrm{E}$ & $622,72-623,08$ & PS3 & $07-173$ & Betuminoso Alto Volátil A & 0,97 & 35,20 & 1,25 & 0,01 & 0,05 & 1,31 \\
\hline \multirow[t]{2}{*}{15} & E & $623,08-623,46$ & PS3 & $07-125$ & Betuminoso Alto Volátil A & 0,71 & 40,34 & 0,95 & 0,03 & 0,04 & 1,02 \\
\hline & E total & $622,34-623,46$ & PS3 & & & 0,86 & 42,23 & 0,95 & 0,02 & 0,04 & 1,00 \\
\hline 16 & $\mathrm{~F}$ & $627,30-627,45$ & PS3 & $07-170$ & Betuminoso Alto Volátil A & 0,91 & 52,15 & 0,80 & 0,00 & 0,03 & 0,83 \\
\hline 17 & G & $631,99-632,35$ & PS2 & $07-174$ & Betuminoso Médio Volátil & 1,19 & 61,93 & 0,52 & 0,00 & 0,02 & 0,55 \\
\hline 18 & G & $632,35-632,72$ & PS2 & $07-175$ & Betuminoso Médio Volátil & 1,11 & 45,63 & 0,50 & 0,03 & 0,02 & 0,55 \\
\hline 19 & G & $632,72-633,08$ & PS2 & $07-164$ & Betuminoso Alto Vblátil A & 0,95 & 53,89 & 0,40 & 0,03 & 0,01 & 0,44 \\
\hline 20 & G & $633,08-633,44$ & PS2 & $07-177$ & Betuminoso Alto Volátil A & 0,94 & 62,75 & 0,66 & 0,00 & 0,02 & 0,68 \\
\hline \multirow[t]{2}{*}{21} & G & $633,45-633,81$ & PS2 & $07-178$ & Betuminoso Alto Volátil A & 1,02 & 53,92 & 0,55 & 0,18 & 0,02 & 0,74 \\
\hline & $\mathrm{G}$ total & $631,99-633,81$ & PS2 & & & 1,04 & 55,76 & 0,52 & 0,04 & 0,02 & 0,59 \\
\hline 22 & $\mathrm{H}$ & $636,47-636,83$ & PS2 & $07-186$ & Betuminoso Alto Volátil A & 0,88 & 46,39 & 0,98 & 0,01 & 0,04 & 1,03 \\
\hline \multirow[t]{2}{*}{23} & $\mathrm{H}$ & $636,83-637,19$ & PS2 & $07-187$ & Betuminoso Alto Volátil A & 0,83 & 63,35 & 0,99 & 0,05 & 0,04 & 1,07 \\
\hline & $\mathrm{H}$ total & $636,47-637,19$ & PS2 & & & 0,86 & 54,63 & 0,98 & 0,03 & 0,04 & 1,05 \\
\hline 24 & I & $637,86-638,22$ & PS2 & $07-181$ & Betuminoso Alto Volátil A & 1,05 & 79,55 & 0,29 & 0,02 & 0,01 & 0,32 \\
\hline
\end{tabular}

PS= paraseqüências; Gás-m= gás medido; Gás-p= gás perdido; Gás-r= gás residual.

ao rank de carvão como indicado pela reflectância da vitrinita.
O valor de enxofre total apresenta uma grande variação desde 0,12 até $7,68 \%$ em peso (Tab. 2). O 
Tabela 2 - Características petrográficas e químicas dos carvões de Santa Terezinha, poço CBM001-ST-RS.

\begin{tabular}{|c|c|c|c|c|c|c|c|c|c|c|c|c|c|c|}
\hline \multirow{2}{*}{ Camada } & \multirow{2}{*}{ Amostra } & \multirow[b]{2}{*}{ Cilindro } & \multirow{2}{*}{$\mathrm{H}_{2} \mathrm{O}$} & \multirow{2}{*}{ Cinza } & \multirow{2}{*}{ M.V. } & \multirow[b]{2}{*}{$\begin{array}{l}\text { Carb. } \\
\text { Fixo }\end{array}$} & \multirow{2}{*}{$S_{t}$} & \multirow[b]{2}{*}{$\begin{array}{c}\mathrm{PC} \\
(\mathrm{kcal} / \mathrm{kg})\end{array}$} & \multirow[b]{2}{*}{$\begin{array}{l}\text { M.V. } \\
\text { (daf) }\end{array}$} & \multirow[b]{2}{*}{$\begin{array}{l}\text { Rrandom } \\
(\%)\end{array}$} & \multicolumn{4}{|c|}{ Análise de Macerais (Vol. \%) } \\
\hline & & & & & & & & & & & Vitrinita & Liptinita & Inertinita & MM \\
\hline A & $07-128$ & 1 & 0,71 & 53,64 & 29,58 & 16,07 & 7,68 & 6265 & 64,80 & 0,65 & 46,6 & 3,4 & 38,6 & 11,4 \\
\hline L1 & $07-114$ & 2 & 1,00 & 92,70 & 5,00 & 1,30 & 0,15 & 170 & 79,37 & 2,61 & 4,4 & 0,0 & 40,6 & 55,0 \\
\hline $\mathrm{L} 2$ & $07-117 / 118$ & 3 & 1,71 & 73,43 & 9,94 & 14,92 & 6,88 & 1490 & 39,99 & 1,50 & 35,0 & 0,4 & 48,0 & 16,6 \\
\hline B & $07-131$ & 4 & 1,36 & 62,17 & 15,02 & 21,45 & 2,58 & 2900 & 41,18 & 0,88 & 37,0 & 0,0 & 36,8 & 26,2 \\
\hline L3 & $07-121$ & 5 & 1,61 & 83,98 & 10,36 & 4,05 & 0,12 & 565 & 71,89 & 1,44 & 1,0 & 0,0 & 44,0 & 55,0 \\
\hline $\mathrm{C}$ & $07-151$ & 6 & 1,41 & 68,07 & 14,65 & 15,87 & 2,06 & 2035 & 48,00 & 0,76 & 31,0 & 11,0 & 39,0 & 19,0 \\
\hline $\mathrm{C}$ & $07-153$ & 7 & 1,53 & 46,39 & 19,73 & 32,35 & 0,41 & 4110 & 37,88 & 0,82 & 42,4 & 5,4 & 44,4 & 7,8 \\
\hline $\mathrm{C}$ & $07-123$ & 8 & 1,50 & 35,40 & 22,73 & 40,37 & 0,70 & 5180 & 36,02 & 0,79 & 42,0 & 8,0 & 38,0 & 12,0 \\
\hline $\mathrm{C}$ & $07-155$ & 9 & 1,33 & 37,09 & 24,82 & 36,76 & 0,48 & 5855 & 40,31 & 0,77 & 46,8 & 9,4 & 35,0 & 8,8 \\
\hline $\mathrm{C}$ & $07-160$ & 10 & 1,08 & 34,43 & 29,03 & 35,46 & 0,31 & 5095 & 45,01 & 0,94 & 46,6 & 5,8 & 34,0 & 13,6 \\
\hline $\mathrm{C}$ total & & & 1,36 & 43,74 & 22,44 & 32,46 & 0,77 & 4499 & 41,45 & 0,82 & 42,0 & 7,9 & 37,9 & 12,3 \\
\hline D & $07-166$ & 11 & 1,44 & 49,34 & 21,26 & 27,96 & 0,31 & 4555 & 43,19 & 0,92 & 47,4 & 8,0 & 34,0 & 10,6 \\
\hline $\mathrm{D}$ & $07-162$ & 12 & 1,13 & 36,03 & 27,57 & 35,27 & 0,68 & 5345 & 43,87 & 0,83 & 45,4 & 10,0 & 33,2 & 11,4 \\
\hline D total & & & 1,27 & 42,08 & 24,70 & 31,95 & 0,51 & 4986 & 43,56 & 0,87 & 46,3 & 9,1 & 33,6 & 11,0 \\
\hline E & $07-168$ & 13 & 1,59 & 55,45 & 17,32 & 25,64 & 0,22 & 3750 & 40,32 & 0,93 & 42,8 & 7,4 & 40,8 & 9,0 \\
\hline E & $07-173$ & 14 & 1,20 & 35,20 & 22,05 & 41,55 & 1,34 & 5295 & 34,67 & 0,97 & 40,0 & 7,0 & 42,0 & 11,0 \\
\hline E & $07-125$ & 15 & 1,56 & 40,34 & 24,35 & 33,75 & 1,18 & 5730 & 41,91 & 0,71 & 46,0 & 5,8 & 31,2 & 17,0 \\
\hline E total & & & 1,43 & 42,23 & 21,72 & 34,62 & 1,00 & 5067 & 38,80 & 0,85 & 42,9 & 6,7 & 37,7 & 12,7 \\
\hline $\mathrm{F}$ & $07-170$ & 16 & 1,41 & 52,15 & 18,45 & 27,99 & 0,27 & 3495 & 39,73 & 0,91 & 32,6 & 5,0 & 55,8 & 6,6 \\
\hline G & $07-174$ & 17 & 1,31 & 61,93 & 13,76 & 23,00 & 0,22 & 2500 & 37,43 & 1,19 & 17,6 & 1,0 & 66,2 & 15,2 \\
\hline G & $07-175$ & 18 & 1,28 & 45,63 & 17,30 & 35,79 & 0,19 & 4150 & 32,59 & 1,11 & 14,6 & 10,0 & 59,4 & 16,0 \\
\hline G & $07-164$ & 19 & 1,24 & 53,89 & 16,64 & 28,23 & 0,20 & 3660 & 37,08 & 0,95 & 18,0 & 12,0 & 60,0 & 10,0 \\
\hline G & $07-177$ & 20 & 1,28 & 62,75 & 15,20 & 20,77 & 0,21 & 2800 & 42,26 & 0,94 & 16,4 & 5,0 & 60,0 & 18,6 \\
\hline G & $07-178$ & 21 & 1,17 & 53,92 & 16,75 & 28,16 & 0,28 & 3565 & 37,30 & 1,02 & 20,4 & 9,6 & 58,0 & 12,0 \\
\hline $\mathrm{G}$ total & & & 1,26 & 55,76 & 15,89 & 27,10 & 0,22 & 3321 & 37,36 & 1,04 & 17,3 & 7,4 & 60,8 & 14,4 \\
\hline $\mathrm{H}$ & $07-186$ & 22 & 0,98 & 46,39 & 22,72 & 29,91 & 1,14 & 4290 & 43,17 & 0,88 & 53,0 & 0,0 & 34,0 & 13,0 \\
\hline $\mathrm{H}$ & $07-187$ & 23 & 0,92 & 63,35 & 17,71 & 18,02 & 1,66 & 2550 & 49,57 & 0,83 & 44,0 & 0,0 & 38,2 & 17,8 \\
\hline $\mathrm{H}$ total & & & 0,95 & 54,63 & 20,28 & 24,13 & 1,39 & 3444 & 46,28 & 0,95 & 48,6 & 0,0 & 36,0 & 15,3 \\
\hline I & $07-181$ & 24 & 1,32 & 79,55 & 10,10 & 9,03 & 1,11 & 1055 & 52,80 & 1,05 & 8,0 & 2,0 & 36,8 & 53,2 \\
\hline
\end{tabular}

M.V.: matéria volátil; Carb. Fixo: carbono fixo; $\mathrm{S}_{\mathrm{t}}$ : enxofre total; P.C.: poder calorífico; daf: dry ash free; M.M.: matéria mineral.

poder calorífico varia desde 170 até $5855 \mathrm{Kcal} / \mathrm{Kg}$ e é das amostras com baixos valores do poder calorífico em diretamente correlacionado para o conteúdo de cinza amostras com alto conteúdo de cinzas e vice-versa. 
Carateristicas do gás associado com as camadas de carvão

VOLUME, COMPOSIÇÃO E ISOTOPOS DE CAR$B O N O$ Resultados das medidas de desorção de metano indicam uma variação entre 0,29 até $2,01 \mathrm{~cm}^{3} / \mathrm{g}$ (Tab. 1). Os volumes de gás perdido são pequenos, variando de 0 à $0,11 \mathrm{~cm}^{3} / \mathrm{g}$, devido ao rápido armazenamento dos testemunhos através de técnicas de wireline. Volumes de gás residual estimados também são pequenos, variando entre 0,01 à $0,06 \mathrm{~cm}^{3} / \mathrm{g}$. As variações do conteúdo de gás associado às camadas de carvão são relacionadas com o conteúdo de cinza (Tab. 1), onde amostras da paraseqüencia 3 , caracterizadas pelo relativo baixo conteúdo de cinza têm os mais altos conteúdos de gás, enquanto que amostras com altos conteúdos de cinza como as camadas L1, L3 e camada I têm o menor conteúdo de gás (Tab. 1).

Os resultados da determinação da composição do gás em amostras selecionadas (Tab. 3) revelaram altos conteúdos de metano (94,26 à 99,47\%), com menores contribuições de hidrocarbonetos como etano, propano, butano e gases não hidrocarbonetos $\left(\mathrm{CO}_{2}\right.$ and $\mathrm{N}_{2}$ ). $\mathrm{O}$ alto conteúdo de $\mathrm{N}_{2}$ observado nos cilindros 23 e 24 não é, até o presente momento, totalmente compreendido e pode ter sido causado por contaminação.

Os valores de isótopos estáveis determinados em amostras selecionadas variam entre $-50,85$ à $-55,54$ $\% \delta^{13} \mathrm{C}$. O metano de origem biogênica é, em geral, enriquecido em isótopos mais leves, quando comparado ao metano de origem termogênico, enquanto o metano com contribuição de ambas fontes apresenta um range de isótopos intermediários (Hunt 1996). Os valores determinados de c-isótopos nos carvões de Santa Terezinha do poço CBM001_ST-RS sugerem uma mistura de gases de origem biogênica e termogênica do metano (Fig. 11).

Cubagem: cálculo de volume de gás natural $\mathrm{A}$ partir da integração entre os dados obtidos nos testes de desorção e os dados volumétricos obtidos através da modelagem, obteve-se um total de 5,482 bilhões de $\mathrm{m}^{3}$ de metano contido no carvão da área considerada no

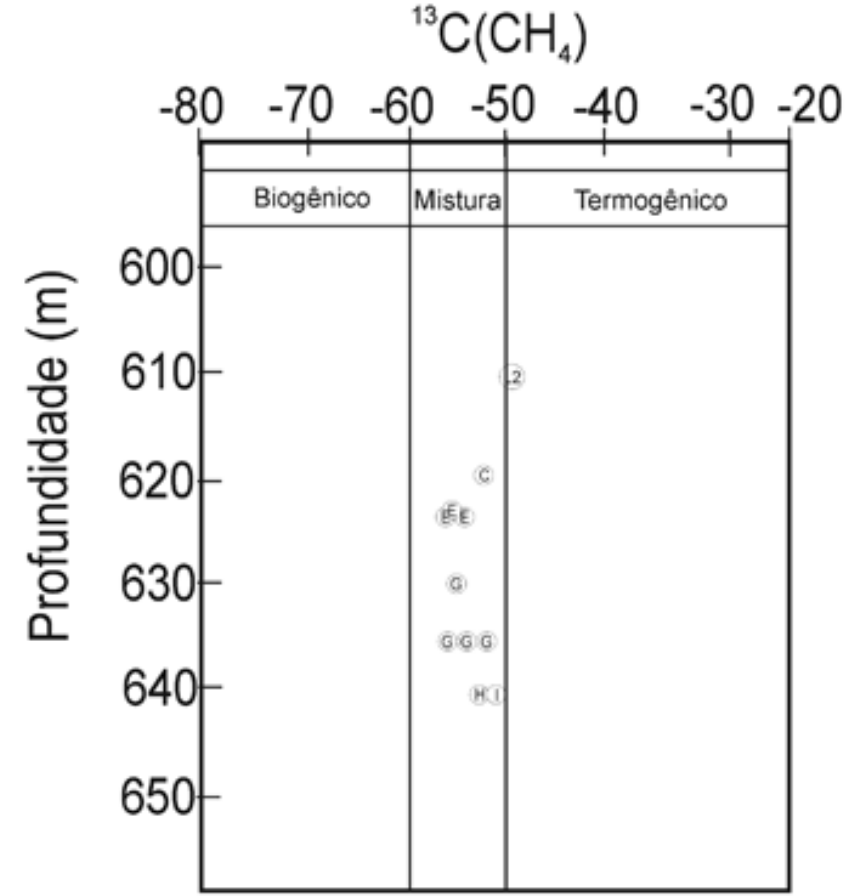

Figura 11 - Valores de isótopos de Carbono versus profundidade sugerindo uma mistura de gases de origem termogênica e biogênica (modificado de Faiz e Hendry 2006).

modelo geológico 3D. Para cada paraseqüência, o conteúdo médio de gás associado com as camadas foi calculado e pesado para a espessura da camada. Os resultados mostraram que as camadas de carvão da paraseqüência 3 têm, em média, um alto potencial CBM $(1,28$ $\mathrm{cm}^{3} / \mathrm{g}$ de carvão). Enquanto que as camadas de carvão na paraseqüência 2 apesar de possuírem o maior volume de carvão, possuem na média um conteúdo de gás muito menor $\left(0,68 \mathrm{~cm}^{3} / \mathrm{g}\right.$ de carvão).

As camadas de carvão nas paraseqüências 4 e 5 têm relativamente altos conteúdos de metano $(0,87$ e $0,96 \mathrm{~cm}^{3} / \mathrm{g}$ de carvão), mas contribuem relativamente pouco para o conteúdo de gás total no depósito devido

Tabela 3 - Composição do gás natural na jazida Santa Terezinha.

\begin{tabular}{c|c|c|c|c|c|c|c|c}
\hline Cilindro & Data & $\mathrm{N}_{2}$ & $\mathrm{C}_{1}$ & $\mathrm{C}_{2}$ & $\mathrm{CO}_{2}$ & $\mathrm{C}_{3}$ & $\mathrm{i}_{4} \mathrm{C}_{4}$ & $\mathrm{n}_{4} \mathrm{C}_{4}$ \\
\hline 3 & $10 / 4 / 2007$ & 0,00 & 97,56 & 1,06 & 0,36 & 0,93 & 0,03 & 0,06 \\
\hline 12 & $25 / 4 / 2007$ & 0,00 & 99,08 & 0,28 & 0,63 & 0,00 & 0,00 & 0,00 \\
\hline 14 & $10 / 4 / 2007$ & 4,79 & 94,26 & 0,22 & 0,73 & 0,00 & 0,00 & 0,00 \\
\hline 14 & $25 / 4 / 2007$ & 0,00 & 99,47 & 0,30 & 0,23 & 0,00 & 0,00 & 0,00 \\
\hline 18 & $11 / 5 / 2007$ & 3,84 & 95,23 & 0,43 & 0,43 & 0,07 & 0,00 & 0,00 \\
\hline 22 & $10 / 4 / 2007$ & 0,00 & 98,39 & 0,61 & 0,85 & 0,15 & 0,00 & 0,00 \\
\hline 22 & $25 / 4 / 2007$ & 0,00 & 97,69 & 0,89 & 1,12 & 0,27 & 0,01 & 0,02 \\
\hline 22 & $11 / 5 / 2007$ & 0,00 & 98,39 & 0,97 & 0,22 & 0,36 & 0,02 & 0,03 \\
\hline 23 e 24 & $5 / 6 / 2007$ & 32,57 & 65,98 & 0,95 & 0,00 & 0,45 & 0,02 & 0,04 \\
\hline
\end{tabular}


ao seu baixo volume de carvão .

CONCLUSÕES (1) A análise estratigráfica seqüencial realizada identificou seis paraseqüências, com o desenvolvimento dos carvões mais importantes na paraseqüência 2 e 3, base de um trato de sistemas transgressivos;

(2) A análise gravimétrica demonstrou a presença e mapeou diques e soleiras de diabásio, que afetam as camadas de carvão. As áreas de ocorrência desses corpos intrusivos, a NE da área de estudo, excluem a princípio aquela região da jazida de Santa Terezinha como potencial para gás metano;

(3) Mesmo com os fatores geológicos negativos como os intensos falhamentos (reativações pós-permianas) que soergueram parte da região e geraram uma extensa discordância (levantando as camadas de carvão a profundidades da ordem de 300 metros) e a presença de diques e soleiras de diabásio, a jazida de Santa Terezinha tem gás metano;

(4) As medidas da reflectância da vitrinita indicam um rank de betuminoso alto volátil C-A com algumas camadas afetadas por intrusões vulcânicas causando um aumento da reflectância da vitrinita correspondente ao nível de carvão betuminoso baixo volátil e semi-antracita;

(5) A análise dos macerais indicam a predominância de inertinita e vitrinita;

(6) A matéria mineral consiste quase inteiramente de quartzo, caolinita e mica, com menor contribuição de pirita, anquerita, calcita, dolomita, albita e alunita;
(7) As camadas mostram enriquecimento das cinzas variando de 34,4 até $93,1 \%$ em peso com o valor médio de $54,00 \%$ em peso;

(8) O valor de enxofre total apresenta uma grande variação desde 0,12 até $7,68 \%$ em peso;

(9) O poder calorífico varia desde 170 até $6265 \mathrm{Kcal} / \mathrm{Kg}$;

(10) As medidas de desorção do gás natural mostra uma variação de 0,32 até $2,18 \mathrm{~cm}^{3} / \mathrm{g}$ de carvão. As variações no conteúdo de gás associadas com as camadas de carvão são relacionadas ao conteúdo de cinza. A composição do gás mostra um alto conteúdo de metano $(94,26$ até $99,08 \%)$ com menores contribuições de $\mathrm{C} 2$ e $\mathrm{C} 3$ e gases não-hidrocarbonetos $\left(\mathrm{CO}_{2}\right.$ e $\left.\mathrm{N}_{2}\right)$. Os valores de isótopos estáveis de carbono $(-50,85$ até $-55,54 \delta^{13} \mathrm{C}$ ) indicam que o metano tem origem térmica e biogênica;

(11) Os volumes de carvão obtidos pela modelagem 3D da área de estudo integrados aos resultados dos testes de desorção (valor médio $=1,004 \mathrm{~cm} 3 / \mathrm{g}$ ) indicam uma reserva de gás da ordem de 5,5 bilhões de metros cúbicos.

Agradecimentos O estudo recebeu apoio financeiro do ANEEL, El Paso do Brasil e Petrobrás. W.K. e M. H. agradecem ao CNPq por bolsa de produtividade em pesquisa, J.C. agradece a ANP por bolsa de mestrado. J. L. agradece a bolsa de mestrado ao CNPq. A composição química do gás natural e os isótopos de carbono foram determinados no Laboratório de Geoquímica do CENPES/ PETROBRAS. Os autores agradecem o apoio.

\section{Referências}

Gentzis T. \& Bolen D. 2008. The use of numerical simulation in predicting the coalbed methane producibility from the Gates coals, Alberta Foothills, Canada. International Journal Coal Geology, 74:215-236.

Faiz M. \& Hendry P. 2006. Significance of microbial activity in Australian coal bed methane reservoirs-A review. Bulletin of Canadian Petroleum Geology, 54:261-272.

Holz M., Kuchle J., Philipp R.P., Arima N., Bishoff A. 2006. Hierarchy of Tectonic Control on Stratigrafic Signatures: Base-level changes during the Early Permian in the Paraná Basin in Southernmost Brazil. Journal of SouthAmerica Earth Sciences, 22:185-204.

Hunt J. 1996. Petroleum Geochemistry and Geology. 2a ed., Freeman e Company, $743 \mathrm{p}$.

ISO-7404/3. 1984. Methods for the Petrographic Analysis of Bituminous Coal and Anthracite. Part 3: Methods for Determining Maceral Group Composition. 1a ed., 4p.

ISO-7404/5. 1984. Methods For the Petrographic Analysis of Bituminous Coal and Anthracite. Part 5: Method of determining Microscopically the Reflectance of Vitrinite. 1a ed., 11p.

Kalkreuth W. \& Holz M. 2000. The coalbed methane potential of the Santa Terezinha coalfield, Rio Grande do Sul, Brazil. Rev. Brasileira de Geociências, 30(3):342-345.

Kalkreuth W., Holz M., Kern M., Burger H., Schauf A., Pris- sang R., Lemos de Sousa, M., C. Rodriguez. 2003. The Coalbed Methane Potential of the Paraná Basin. In: Congresso Brasileiro de P\&T em Petróleo e Gás, 2, Rio de Janeiro, anais, p.1-6, CD ROM.

Kern M.L. 2002. Avaliação do potencial gerador de metano das jazidas de Chico Lomã e Santa Terezinha, nordeste do Rio Grande do Sul. Dissertação de Mestrado, PPGEO/IG-UFRGS, Porto Alegre, 182p.

Milani E.J. 2000. Geodinâmica Fanerozóica do Gondwana sul-ocidental e a Evolução Geológica da Bacia do Paraná. In: Holz M. \& deRos L.F. (eds.) Geologia do Rio Grande do Sul. Edição CIGO/UFRGS, p. 275-302.

Murray D. 1996. Coalbed methane in the U.S.A.: analogues for worldwide development. In: Gayer R. \& Harris I. (eds.) Coalbed methane and Coal Geology. London, Geological Society Special Publication, 109, p.1-12.

Zalán P.V., Wolff S., Conceiçao J.C.J., Marques A., Astolfil M.A.M., Vieira I.S., Appi V.T., Zanotto O.A. 1990. A Bacia do Paraná. In: Raja Gabaglia G.P. \& Milani E.J. (coords.) Origem e Evolução de Bacias Sedimentares. Rio de Janeiro, PETROBRÁS, p. 135-168.

Manuscrito BR 16

Submetido em 20 de janeiro de 2008 Aceito em 26 de março de 2008 